Edição especial: 25 anos do Programa de Pós-Graduação em Meio Ambiente e Desenvolvimento Vol. 47, outubro 2018. DOI: 10.5380/dma.v47i0.62430. e-ISSN 2176-9109

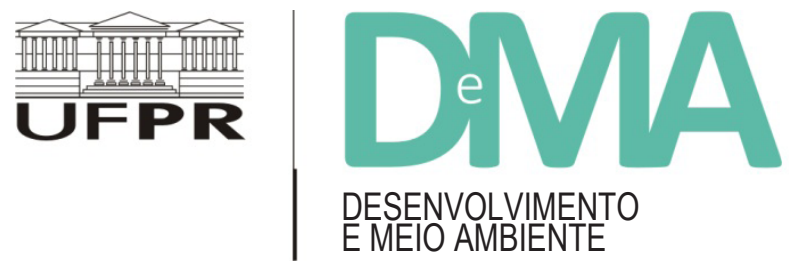

\title{
Aspectos do perfil dos egressos do PPGMADE em 22 anos e o efeito multiplicador da formação dos Doutores
}

\section{Profile aspects of PPGMADE graduates from the last 22 years and the multiplier effect of the training of Doctors}

\author{
Cristina de Araújo LIMA ${ }^{1 *}$, Rafaela Antunes FORTUNATO ${ }^{1,2}$ \\ ${ }^{1}$ Programa de Pós-Graduação em Meio Ambiente e Desenvolvimento (PPGMADE), Universidade Federal do Paraná(UFPR), Curitiba, PR, Brasil. \\ ${ }^{2}$ Universidade Tecnológica Federal do Paraná (UTFPR), Curitiba, PR, Brasil. \\ *E-mail de contato: cristinadearaujolima@gmail.com
}

RESUMO: O presente artigo tem o objetivo de analisar o perfil dos egressos do Programa de Pós-Graduação em Meio Ambiente e Desenvolvimento da Universidade Federal do Paraná - UFPR - PPGMADE - em 22 anos, refletindo a respeito do seu efeito multiplicador na formação de doutores. O método utilizado é a matriz de correlações, utilizando como fonte de pesquisa os dados coletados no PPGMADE e também na Plataforma Lattes, do CNPq. Tem-se, como pressuposto, que a maioria dos doutores formados pelo PPGMADE tem atuação na docência, o que permite uma ampliação de suas pesquisas dentro do ambiente acadêmico, redistribuindo os saberes e oportunidades para os seus alunos. Constatou-se que grande parte dos doutores "madeanos" (oriundos do PPGMADE) continuam atuando em suas áreas de pesquisa - sendo que, destes, 84,33\% são professores universitários; líderes e/ou participantes de grupos de pesquisa; realizadores de projetos de extensão junto a comunidades; formadores de opinião e continuam publicando suas pesquisas em periódicos científicos, eventos, mídia, capítulos de livros e livros. Além disso, 48,23\% das formações do PPGMADE são de mulheres, o que mostra um avanço para uma situação mais equilibrada entre gêneros nesse âmbito de ensino.

Palavras-chave: perfil de egressos de doutorado; PPGMADE/UFPR 22 anos; ensino de pós-graduação; atividade científica.

ABSTRACT: This article aimed to analyze the profile of graduates from the Postgraduate Program in Environment and Development (Programa de Pós-Graduação em Meio Ambiente e Desenvolvimento - PPGMADE) of the Federal University of Paraná (Universidade Federal do Paraná - UFPR) from the last 22 years, reflecting on 
its multiplier effect in the training of doctors. The method used was the correlation matrix, using as research source the data collected from PPGMADE and Plataforma Lattes, from CNPq (Brazilian National Research Council). It is assumed that the majority of the doctors trained by the PPGMADE have a teaching role, which allows them to expand their research within the academic environment, redistributing knowledge and opportunities to their students. It was found that a large portion of the PPGMADE doctors continue to work in their research areas, with $84.33 \%$ acting as university professors, leaders and participants of research groups, extension project leaders working with communities, opinion formers, and also contine to publish their research in scientific journals, events, media, chapters of books and books. In addition, $48.23 \%$ of the PPGMADE graduates are women, which shows an advance towards a more balanced gender situation in this field of education.

Keywords: PhD graduate profile; PPGMADE/UFPR 22 years; postgraduate teaching; scientific activity.

\section{Introdução}

O Programa de Pós-Graduação PPGMADE realiza a proposta de aprofundar o estudo, o questionamento e a reflexão a respeito do que é, ou possa vir a ser, "desenvolvimento" em sua relação com o Meio Ambiente. Para isso trabalha desde as bases conceituais, passando pelo processo histórico, sociocultural, ideológico do contexto da globalização e do país, para discutir recortes específicos - sejam geograficamente definidos ou não, em suas problemáticas, potencialidades e alternatividades. Para dar conta dessa missão, o PPGMADE foi criado com objetivo de formar pessoas e, no âmbito do programa de doutorado (o mestrado é opção mais recente do programa), vem oferecendo atividades didáticas de ensino, pesquisa e extensão, realizadas ao longo dos últimos 22 anos, a partir de 1993,-um ano após a realização da Conferência das Nações Unidas sobre Meio Ambiente e Desenvolvimento na cidade do Rio de Janeiro, conhecida como 'RIO 92'. O PPGMADE foi um programa pioneiro quando a temática ambiental era algo novo no panorama da pós-graduação nacional (Philippi, 2000).

A formação de quadros competentes para definir políticas e ações voltadas para o desenvol- vimento, é uma pauta de interesse universal e que, em cada sociedade, é realizada conforme um trajeto próprio, determinado por condicionantes, circunstâncias e oportunidades resultantes de um conjunto articulado de forças, interesses e limitações sociais, políticas, econômicas e culturais. $\mathrm{O}$ aparecimento tardio das universidades brasileiras, em comparação com as universidades latino-americanas, explica em parte - o surgimento, no início do século XX, de uma pesquisa científica de lento desenvolvimento, como salientam Moritz et al. (2011). Mas, graças a iniciativas como da criação do PPGMADE, a Pós-Graduação no Brasil passa - atualmente - por um período de avanço significativo, tanto em relação ao número de cursos e programas (em diferentes campos do conhecimento), quanto em relação ao aumento da quantidade de publicações científicas, fruto de pesquisas que, em grande parte, contam com a participação dos alunos dos cursos stricto sensu.

A pós-graduação brasileira deslanchou após 1990, com resultados crescentes nos rankings nacional e internacional. Na primeira década do século XXI, o Brasil atingiu a $13^{\text {a. }}$ posição na produção científica mundial, com conteúdos de destaque em eventos, publicações, fóruns e organismos nacionais 
e internacionais (Gianetti, 2010 apud Moritz et al., 2011). Estes autores confirmam que essa condição se deve à pós-graduação, uma realidade que vem se consolidando nos últimos anos.

Portanto, refletindo sobre a pós-graduação no Brasil, cabe avaliar um programa inovador no contexto brasileiro - o PPGMADE -, que traz como premissa a interdisciplinaridade (Floriani, 2000; Leff, 2000), uma proposta de iniciativa de um grupo de professores brasileiros e franceses fundadores do programa, com destaque para os doutores Magda Zanoni e Claude Raynaut. Esses, no prefácio do primeiro número da revista Desenvolvimento e Meio Ambiente (inicialmente chamada de 'Cadernos'), comemoravam a criação do curso de doutorado e a atribuição de uma Cátedra da UNESCO para o Desenvolvimento Sustentável ao programa recém-criado, "como reconhecimento da originalidade de um processo que ela (a UFPR) havia desencadeado com a criação deste curso interdisciplinar" (Raynaut \& Zanoni, 1994, p. 11).

Também, Raynaut \& Zanoni (1994) salientaram a concretização do programa como o coroamento de vários anos de trabalho realizado previamente à sua fundação, com atuação em múltiplas frentes em dois países, a partir de reflexão teórica sobre a relação sociedade-natureza; entre meio ambiente e desenvolvimento; entre ciência e prática. No texto, os autores citavam o impulso inicial para a criação do PPGMADE, dado em 1990, na UFPR. Isso aconteceu pela realização de um Seminário Internacional sobre o enfoque interdisciplinar no campo do desenvolvimento; de uma fase de síntese e debates ampliados em julho de 1993 com a realização de um Colóquio Internacional sobre as Cátedras UNESCO para o desenvolvimento sustentável.
Finalmente, era ressaltado o trajeto exemplar de parceria e complementaridade entre a UFPR e as instituições francesas de ensino superior - por meio de alguns dos seus fundadores: a Universidade de Paris 7, onde trabalhava a Professora Magda Zanoni; a Universidade de Bordeaux 2, local de trabalho do Professor Claude Raynaut; a Escola de Altos Estudos em Ciências Sociais, em Paris, de onde Ignacy Sachs interagia com o mundo; e a Escola de Arquitetura de Paris - La Villette, espaço de ensino e pesquisa do arquiteto Professor Yanis Tsiomis. Cabe ainda lembrar a essência da proposta do Made, como um fórum de pesquisa e discussão interdisciplinar a respeito da questão socioambiental para questionar posições e práticas hegemônicas, como expressa Floriani:

A emergência da questão ambiental, em escala global, é um complicador para a organização assimétrica do poder mundial, abrindo novas tensões em relação à apropriação dos recursos naturais, que começam a escassear, e a consequente politização entre países e regiões detentores de um "capital natural" e demais países detentores de tecnologia. $\mathrm{O}$ confronto não se limita apenas a questões econômicas, politicas e tecnológicas, mas também éticas, filosóficas e culturais, configurando um novo campo de disputas simbólicas sobre a vida, a natureza, o desenvolvimento... (Floriani, 2006, p. 76).

Portanto, durante a organização do evento que comemorou os 22 anos do PPGMADE (realizado em 2015 na UFPR em Curitiba), a motivação de sistematizar dados, referentes aos doutores formados pelo programa, se fortaleceu pela convicção da importância do papel desempenhado pelo programa em sua trajetória. Na ocasião da comemoração, pela presença de muitos ex-alunos e professores, 
teve-se notícia ou confirmação de que um grande número deles atuava no ensino universitário em diversas partes do país - como professores, como agentes criadores de programas de graduação e pós-graduação e, também, vários que se tornaram integrantes do corpo docente do próprio PPGMA$\mathrm{DE}$, ou formaram grupos de pesquisa, orientavam jovens estudantes de graduação e pós-graduação, entre outras iniciativas coerentes com os objetivos madeanos típicos, quanto à formação e interdisciplinaridade.

Para verificar o perfil dos egressos foram utilizados os dados cadastrados na Plataforma Lattes (CNPq), tais como as características desses doutores quanto à gênero, nacionalidade, produtividade e área de atuação. Esses dados permitiram verificar o quanto a participação no PPGMADE contribuiu para que os mesmos pudessem se tornar, ou se aperfeiçoar como atores expressivos no seu contexto sociocultural e profissional. Cabe ressaltar que a base de dados que permite, agora, avaliar alguns resultados de um programa de pós-graduação, e se constituir em suporte para a continuidade de uma atuação segura e direcionada, vem sendo semeada há poucas décadas no Brasil.

Desde meados da década de 1980, existia a preocupação na criação de uma base de dados que possibilitasse a avaliação dos pesquisadores brasileiros, agregando informações que contribuíssem para a geração de estatísticas sobre a pesquisa científica no Brasil. Com esse objetivo, em 1999, o CNPq lançou e padronizou o Currículo Lattes. Essa plataforma está em constante atualização, sendo amplamente utilizada pelos programas de pós-graduação no Brasil e, a partir de 2002, em diversos países da América Latina - como Colômbia, Equador, Chile, Peru, Argentina, além de Portugal,
Moçambique e outros que se encontram em processo de implantação (CNPq_b, 2016).

Conforme dados do Ministério da Ciência e Tecnologia (2016), o Brasil encontra-se em $23^{\circ}$ no ranking global quanto à produção científica, e primeiro lugar na América Latina. Apesar de ocupar o primeiro lugar na América Latina, o Brasil ainda possui inúmeros desafios, que se serão comentados durante esse artigo.

\section{A formação do profissional: professor e pesquisador}

Rosa \& Schnetzler (2003), defendem que o ensino e a pesquisa estejam inter-relacionados na formação continuada de professores, de modo a fomentar uma atitude crítica dos mesmos em face a realidade, num processo de ensino-aprendizagem focado na investigação-ação. Para as autoras, "para que a espiral auto reflexiva se desenvolva no sentido da investigação-ação não é suficiente que professores se sintam simplesmente abertos e disponíveis para conversar sobre suas práticas. É necessário que cada um traga, dentro de si, questões de investigação que o mobilizem na direção de novos planejamentos, novas ações e reflexões" (Rosa \& Schnetzler, 2003, p. 33).

Os autores Lima et al. (2015, p. 40) também defendem a formação de um professor-pesquisador. Segundo eles, "ao propormos o professor como pesquisador não estamos acrescentando mais um trabalho para o professor, estamos considerando que esse tipo de pesquisa é parte de seu processo de formação continuada e essencial a seu exercício profissional". 
Todavia, Gatti (2001) ressalta que, apesar da formação de professores e pesquisadores serem realizadas simultaneamente (devido aos prazos) nos programas de mestrado e doutorado no Brasil, muitas vezes os programas acabam optando por escolher entre valorizar mais a pesquisa que a própria formação do professor.

Essa autora cita Guadilla (1997), que comenta que a partir da década de 1990 aumentou a participação de agentes de fora da universidade, ligados a novos sistemas produtivos, que demonstram interesse maior pela participação em programas de pós-graduação. Esses novos atores sinalizavam a passagem de uma etapa civilizatória à outra, que implica na desvalorização repentina de um capital cultural e alteração de relações de poder já instituídas. Nesse caso, especificamente, a formação do professor-pesquisador ultrapassa os contornos do âmbito acadêmico, uma vez que esses novos agentes vão buscar a capacitação por meio da pesquisa e pela atuação no mercado de trabalho, não relacionado com a educação superior.

Além desses aspectos, conforme Gasque \& Tescarolo (2008, p. 147), a educação deve primar pelo emprego da pedagogia do equilíbrio, que integre - em sua formação - as dualidades existentes entre "certeza com dúvida; convicção com hesitação; verdade com crença; ciência com consciência; racionalidade com intuição; razão com sensibilidade, como totalidade em movimento em busca de transcendência, do que está além, antes e acima de nós".

Buscando esse equilíbrio, o PPGMADE - que tem como problemática fundadora a relação entre meio ambiente e desenvolvimento - vem exercitando o diálogo de saberes por meio da interdisciplinaridade, assumindo e exercitando a pluralidade dos atores. Assim, a metodologia interdisciplinar, desempenhada pelo PPGMADE, consegue agregar tanto aspectos da formação do professor-pesquisador, incentivadas por Rosa \& Schnetzler (2003) e Lima et al. (2015), quanto agregar à capacitação dos novos agentes que buscam um programa de doutorado como debate e ampliação do seu campo de pesquisa e atuação, como comentam Guadilla (1997) e Gatti (2001).

\section{Efeito multiplicador dos egressos}

Quando se pensa nas práticas desenvolvidas dentro de um programa de pós-graduação, nota-se questões para além da participação no período da formação, e que são relacionadas ao efeito multiplicador produzido pelos formandos do mesmo, após a conclusão do programa. $\mathrm{O}$ efeito se realiza, tradicionalmente, no meio acadêmico por meio de funções que podem ser exercidas de forma simultânea ou não, como:

- professores em relação a seus alunos e orientados;

- líderes de grupos de pesquisa no âmbito acadêmico;

- realizadores de projetos de extensão junto a comunidades delimitadas e/ou público em geral;

- formadores de opinião com participação na mídia, por meio da participação em debates de questões emergentes ligadas à vida comunitária nacional ou internacional; por meio de artigos, entrevistas, participação em reportagens; realizadores e participantes de eventos de alcance aos variados segmentos da população, inclu- 
sive alimentando canais universitários de

$\mathrm{TV}$, rádio e Internet.

A contribuição dos egressos de cursos de pós-graduação se alcança, tanto de forma direta quanto indireta, na esfera acadêmica e fora dela. A influência se estabelece desde os marcos teóricos do ensino universitário, como autores e/ou como docentes, como também na função de administradores universitários, como técnicos e assessores nas instituições governamentais e não governamentais; nas empresas e órgãos de natureza mista e em comunidades nas variadas escalas.

Além disso, na vida pública sua influência pode advir da atuação acadêmica e científica, passando ao exercício de cargos administrativos, de funções políticas com atribuição de legislar ou executar políticas públicas.

Essas características dos egressos serão avaliadas neste artigo por meio da matriz analítica selecionada - formada por categorias de análise que serão explicadas com maiores detalhes no item "Aspectos Metodológicos".

\section{Gênero na pós-graduação}

A questão de gênero se constitui em um dos desafios brasileiros de transformar em realidade o que é previsto em lei. Alves (2016) comenta o avanço das mulheres em muitas áreas, apontando que elas vêm superando os homens, sendo que $60 \%$ das formações de ensino superior são femininas. Contudo, essa melhoria na formação não está refletida ainda no mercado de trabalho, onde além da participação ser inferior à masculina, os salários continuam (sistematicamente) abaixo dos homens. Todavia, a Figura 1 mostra a classificação da Capes no Brasil, quanto aos doutores e mestres por sexo. Nos programas de doutorado e mestrado as mulheres representam, respectivamente, 47,5\% e 53,4\%.

No PPGMADE essa relação é um pouco maior, apresentando 48,23\% de mulheres e 51,77\% de homens, como mostrado na Figura 2 (no item 6, a seguir), o que demonstra um pequeno avanço em relação à média nacional.

\section{Aspectos metodológicos}

O método utilizado para análise do perfil dos egressos em 22 anos do PPGMADE, é a matriz de correlações, utilizando como fonte de pesquisa os dados cadastrados no PPGMADE, e também na Plataforma Lattes, do CNPq (CNPq_c). As informações foram organizadas pelas autoras (Lima \& Fortunato, 2016), na forma de tabela do programa Excel. Conforme descrito anteriormente, foi buscada uma base de dados que possibilitasse a avaliação dos pesquisadores brasileiros, o que se constitui no Currículo Lattes - constante na Plataforma Lattes, o qual permite agregar informações que contribuem para a geração de estatísticas sobre a pesquisa científica no Brasil. Outra vantagem do Lattes é que essa plataforma está em constante atualização, sendo amplamente utilizada pelos programas de pós-graduação no Brasil e, a partir de 2002, disponibilizada gratuitamente para diversos países latino-americanos, além de oferecer consultoria técnica para sua implantação (CNPq_b, 2016).

Contudo, deve-se considerar que a atualização dos dados do currículo Lattes é realizada por cada pesquisador, sendo a atualização e veracidade dos dados de sua responsabilidade. Dos 141 doutores formados pelo PPGMADE, no período de 1993 a 
2016, 16 destes (cerca de 11\% de todos os dados analisados), no período em que foi elaborada a matriz analítica - de 04 de julho de 2016 à 27 de setembro de 2016 - não estavam cadastrados na Plataforma Lattes ou a mesma se encontrava desatualizada.

Quanto aos aspectos avaliados, com base no aporte teórico aplicado neste artigo, foram selecionados dados de cinco categorias: a) de caráter pessoal; b) relacionados à tese e condições do período de doutoramento; c) de formação - pré e pós-doutoramento; d) de produção bibliográfica; e) da ocupação atual - pós-doutoramento.

Assim, os dados avaliados para cada um dos 141 doutores formados pelo PPGMADE, no período de 1993 a 2016, em 12 turmas foram: gênero, nacionalidade, vínculo dos orientadores (PPGMA$\mathrm{DE}$, universidade nacional ou estrangeira), linha

\section{Doutores por sexo}

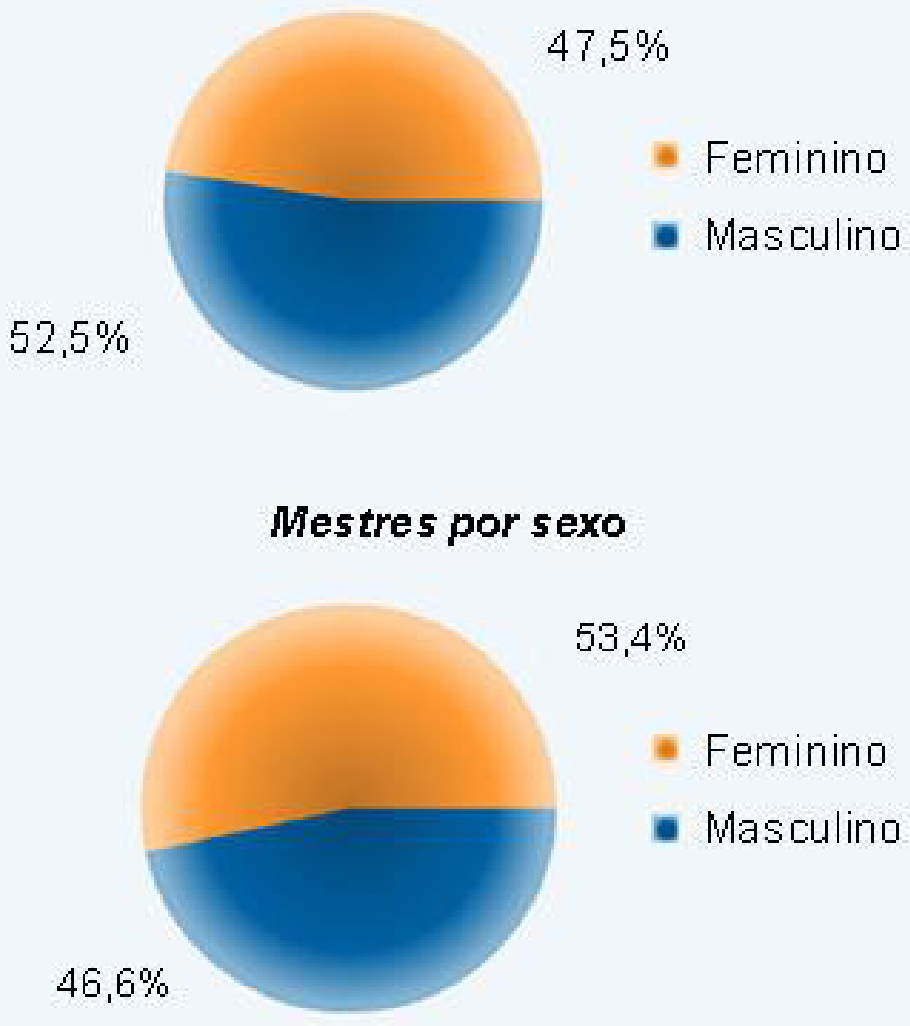

FIGURA 1 - Classificação da CAPES no Brasil - Doutores e mestres por Sexo.

FONTE: CNPq | Plataforma Lattes (2016). 
de pesquisa das teses (rural, urbano, epistemologia ou costeiro), recorte espacial das teses (Curitiba, Região Metropolitana de Curitiba - RMC, Paraná, Brasil ou internacional), tempo de conclusão das teses (3 a 7 anos), formação dos doutores (antes do curso de doutorado: mestrado, especialização e graduação na UFPR; ou pós-doutorado), produção bibliográfica (projeto de pesquisa ativo, artigos em periódicos científicos, livros e capítulos de livros) e ocupação atual (professor de ensino universitário, professor ou técnico aposentado, técnico de órgão público, professor de ensino médio, ativista ambiental, cargo de direção em instituição pública ou não atuante na área).

Os resultados foram processados com uso do software Excel, a fim de serem obtidas as quantidades parciais ou totais, as proporções e/ou as porcentagens de cada variação de subtema. Os números obtidos subsidiaram a análise e as considerações sobre o conteúdo, verificando-se cada um dos 141 doutores formados pelo PPGMADE no período desde sua criação até 2016, nas cinco categorias citadas acima.

\section{Análise do perfil dos egressos do PPGMADE em 22 anos}

Buscando cumprir o objetivo do artigo, de conhecer o perfil dos egressos do PPGMADE no período de 1993 a 2016, inicialmente observou-se os dados obtidos para 4 tópicos, sendo, pela ordem: a) a questão do gênero dos egressos; b) a nacionalidade; c) o vínculo do orientador principal (se membro do PPGMADE, de outro programa/ universidade brasileira ou de universidade estrangeira); o local do recorte (sendo opções: Curitiba, RMC, Paraná, Brasil ou recorte internacional).

Em relação à questão de gênero, foi verificado que a participação das mulheres no total dos egressos do PPGMADE é de 48,23\%, corroborando com as indicações de Alves (2016) para o caso brasileiro, porém com diferença pequena em relação aos egressos do sexo masculino. Esta proporção de egressos do sexo feminino se situa próxima da situação registrada no censo realizado pelo $\mathrm{CNPq}$, quanto ao conjunto de programas de pós-graduação stricto sensu no país, no qual as mulheres representam respectivamente $47,5 \%$ e $53,4 \%$ (CNPq_a, 2016).

Contudo, esta situação de proximidade nos resultados relativos a gênero, não se aplica para a questão da nacionalidade, pois $97,87 \%$ dos doutores formados pelo PPGMADE são brasileiros e também os seus orientadores principais, o que abrange cerca de $90 \%$ dos casos com professores "da casa", ou seja, que fazem parte do corpo docente do PPGMADE. No entanto, cerca de $10 \%$ dos orientadores principais são provenientes de outras universidades nacionais ou estrangeiras - o que mostra alguma comunicação importante com outras instituições para a função crucial de orientador principal da tese (Figura 2).

Já a localização do recorte espacial das teses, configura um resultado mais distribuído, sendo que se equiparam as proporções de recortes situados no Estado do Paraná com aqueles localizados na RMC, ambos coincidentes em $31,08 \%$. Ainda quanto ao recorte, é interessante notar que os estudos sobre Curitiba não são em número muito superior àqueles que escolheram recortes localizados em outros locais do território nacional, o que pode indicar que a capital paranaense não vem se constituindo em recorte tão frequente quanto seria possível imaginar, 
tendo em vista a localização do PPGMADE na própria cidade, capital do Estado do Paraná (Figura 2).

Em relação ao tempo de conclusão da tese, os números mostram que em quase $60 \%$ dos casos, as mesmas foram finalizadas no prazo de quatro anos, o que indica uma adequação ao que é estabelecido e prescrito pelos órgãos normativos federais - que determinam os prazos e os monitoram. Contudo, duas situações chamam a atenção ao mostrar uma similaridade: as teses finalizadas no prazo de cinco anos $(28,37 \%)$ com aquelas que foram concluídas no prazo máximo captado nos registros, que foi de sete anos para conclusão do doutoramento. No outro extremo, se encontra a quantidade de teses finalizadas antes de quatro anos $1,42 \%$, que coincide com a quantidade de teses que tomaram seis anos para sua elaboração (Figura 3). Cabe considerar que em parte do tempo de existência do PPGMADE, o prazo máximo de conclusão do doutoramento era de cinco anos.

Outra característica, do processo de doutoramento, que foi levantada se deve à distribuição da quantidade de teses por linhas de pesquisa. O PPGMADE possui 4 linhas de pesquisa, que são:

\section{PPGMADE (1993 A 2016): NACIONALIDADE DOS DOUTORES FORMADOS}

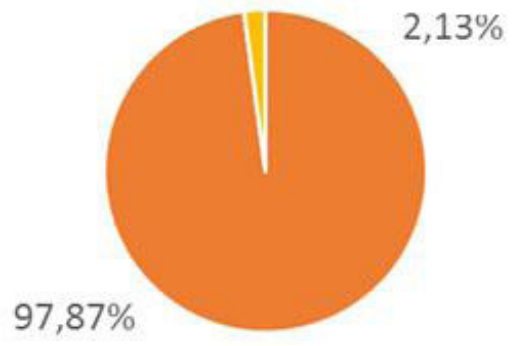

= BRASILEIRO

- ESTRANGEIRO

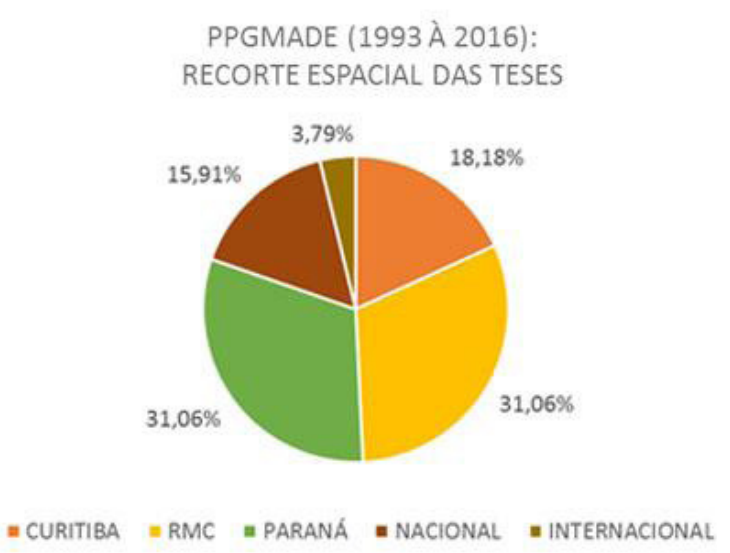

FIGURA 2 - PPGMADE (1993 a 2016): perfil dos egressos quanto à gênero e nacionalidade dos doutores formados, vínculo dos orientadores e recorte espacial das teses.

FONTE: Elaborado pelas autoras com base no CNPq | Plataforma Lattes (2016). 


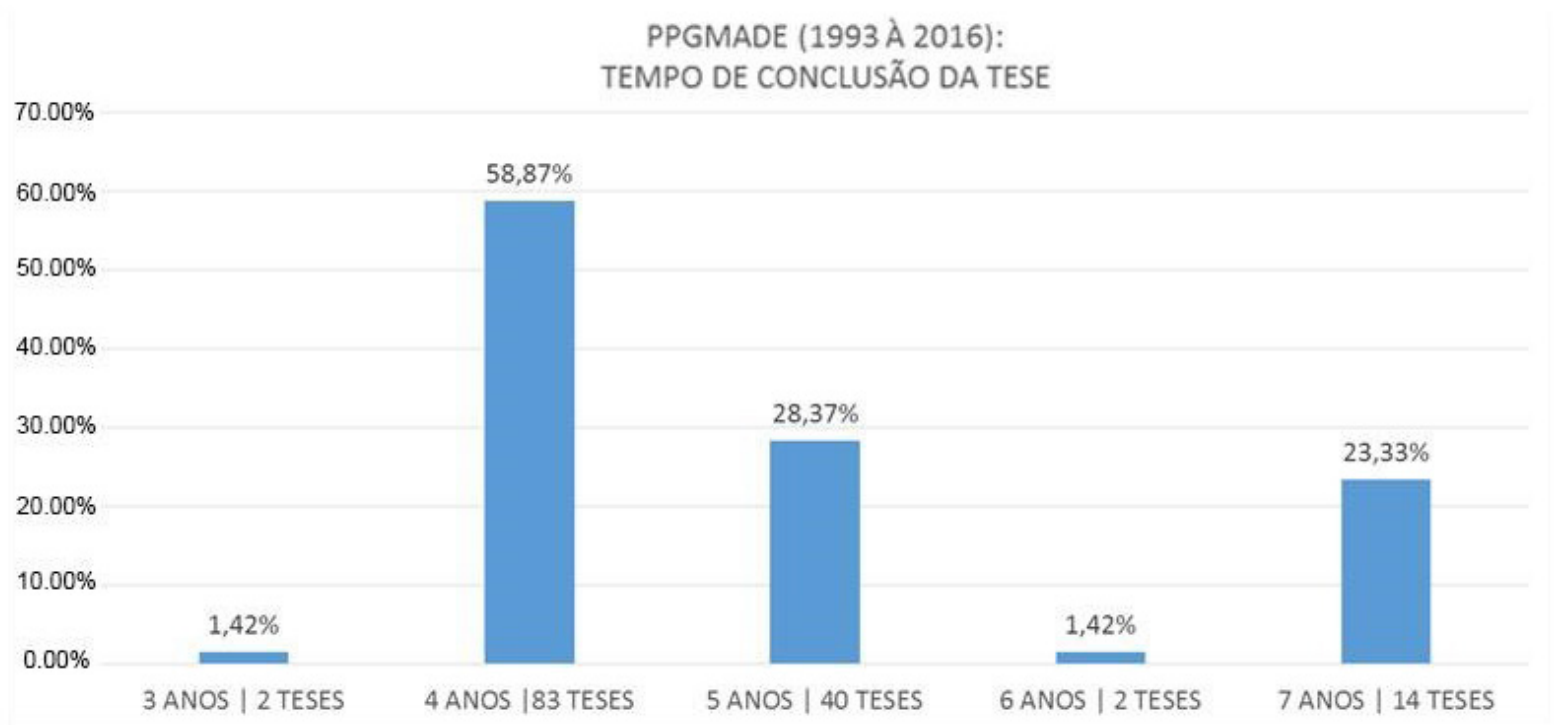

FIGURA 3 - PPGMADE (1993 a 2016): tempo de conclusão da tese.

FONTE: Elaborado pelas autoras com base no CNPq | Plataforma Lattes (2016).

Costeiro, Epistemologia, Rural e Urbano. Essas, se dedicam aos temas e recortes de estudo relacionados aos âmbitos e contextos específicos. Cabe aqui ressaltar que as linhas foram criadas na Turma III de doutorado (1998-2002), desconfiguradas em duas turmas seguintes (VII e VIII) e, em seguida, retomadas. Sendo que, a partir de 2016, começam a existir também dois núcleos temáticos que se intitulam "Energia" e "Direito e Justiça Ambiental - EKOA". Nos números levantados para as 141 teses do período entre 1993 e 2016, considerando as quatro linhas de pesquisa, verificou-se que a maioria das teses foi desenvolvida na Linha do Urbano (30,28\%), seguida pela Linha Rural (26,06\%), enquanto as outras duas linhas (Epistemologia e Costeiro) apresentaram o mesmo número de teses, 31 no total, conforme é possível ver na Figura 4.
A atividade profissional dos egressos do PPGMADE, registrada pelos números levantados, veio corroborar uma espécie de pressuposto geral dentre a comunidade madeana: de que a maioria dos egressos era formada por professores universitários $(84,33 \%)$. Os números vieram dar um suporte quantitativo à essa suposição, que era comentada na condição de opinião, antes do levantamento realizado. A prática docente, apesar de ser a atividade da grande maioria dos egressos do PPGMADE, não é a única, sendo que o trabalho na função de técnico de instituição pública se apresenta como uma outra opção em quantidade expressiva, em torno de $12 \%$. Por outro lado, verificou-se que a proporção de profissionais aposentados nestes 22 anos é bastante pequena $(0,75 \%)$, segundo os dados que os egressos do PPGMADE apresentam nos seus currículos LATTES (Figura 5). 


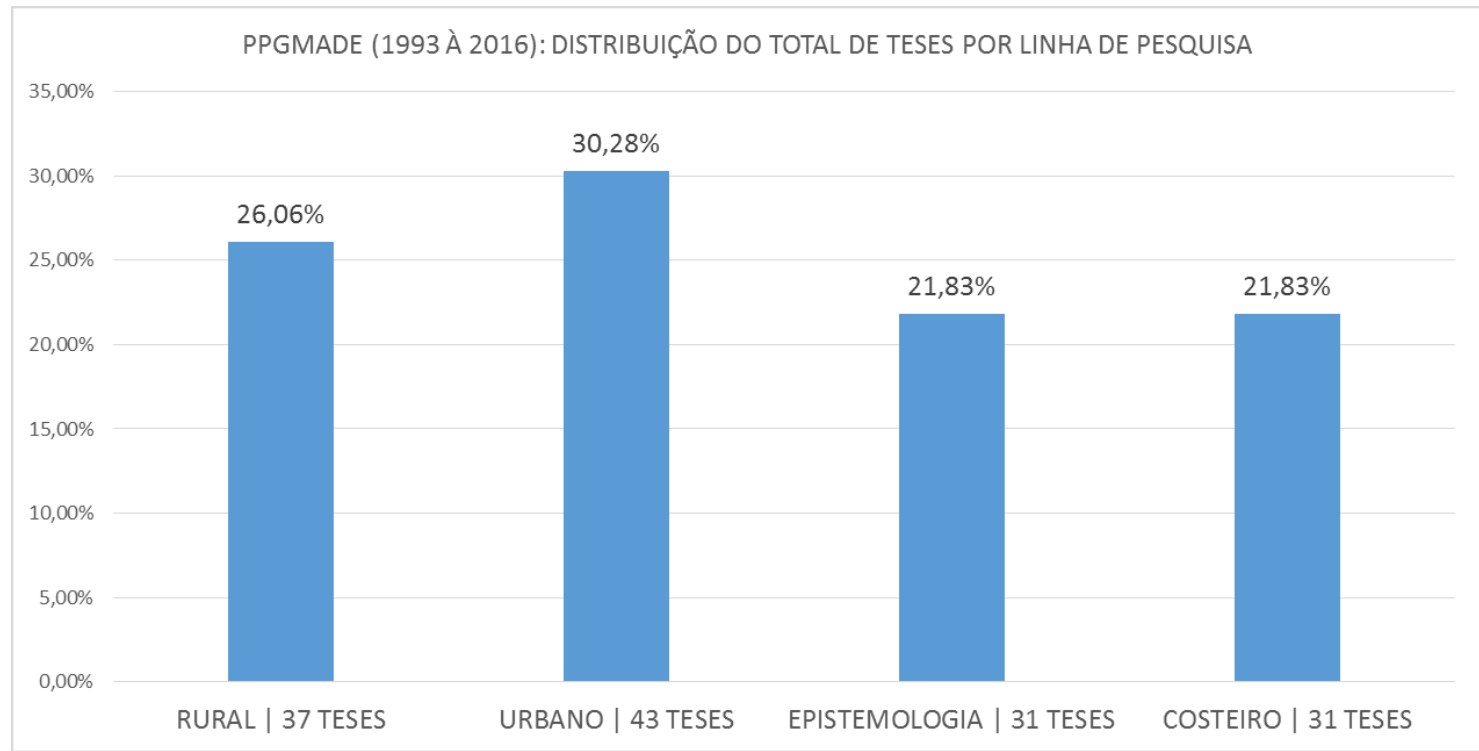

FIGURA 4 - PPGMADE (1993 a 2016): distribuição total de teses por linha de pesquisa.

FONTE: Elaborado pelas autoras com base no CNPq | Plataforma Lattes (2016).

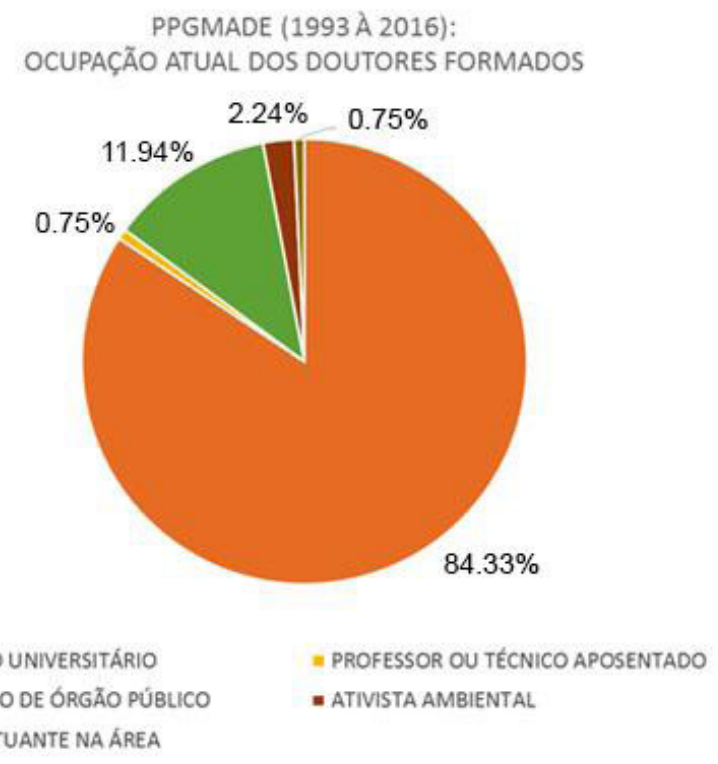

FIGURA 5 - PPGMADE (1993 a 2016): ocupação atual dos doutores formados.

FONTE: Elaborado pelas autoras com base no CNPq | Plataforma Lattes (2016). 
Ao se considerar que quase $85 \%$ dos doutores, formados no PPGMADE, atuam como professores universitários, é pertinente a verificação da sua formação, antes e depois do doutoramento. Quan-

TABELA 1 - PPGMADE (1993 a 2016): matriz de análise da titulação e produção dos 141 doutores formados.

\begin{tabular}{lc}
\hline \multicolumn{1}{c}{ Titulação e produção } & Número \\
\hline Titulação & 34 \\
Pós-Doutorado & 114 \\
Mestrado & 99 \\
Especialização & \\
Produção bibliográfica & 185 \\
Projeto de pesquisa & 1735 \\
Artigo publicado em periódico & 785 \\
Capítulo de livro & 288 \\
Livro &
\end{tabular}

FONTE: Elaborado pelas autoras com base no CNPq | Plataforma Lattes (2016). to a isso, os dados mostram que dos 141 doutores formados no período, havia registro de 114 cursos de mestrado concluídos - com a ressalva de que há casos, raros, de dois mestrados realizados pela mesma pessoa. Quanto às condições no período de pós-doutoramento, os dados apontam que 34 dos doutores prosseguiram para outros estudos na forma de um pós-doutoramento, sendo que esta quantidade indica que essa prática ainda não se constitui em opção frequente dentre os egressos. As razões dessa situação poderiam ser um tema interessante para uma próxima etapa de pesquisa (Tabela 1).

Finalmente, uma situação considerada muito importante - que é a produção bibliográfica. No período analisado, os egressos do PPGMADE produziram 1735 artigos, publicados em periódicos de variadas classificações no Sistema Qualis da

\section{PPGMADE (1993 À 2016): TIPOLOGIA DA PRODUÇÃO BIBLIOGRÁFICA}

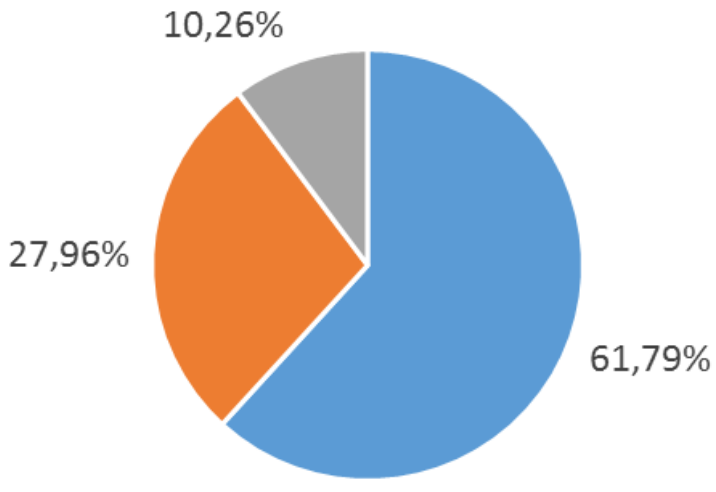

\section{- ARTIGO PUBLICADO EM PERIÓDICO = CAPÍTULO DE LIVRO = LIVRO}

FIGURA 6 - PPGMADE (1993 a 2016): tipologia da produção bibliográfica dos doutores formados.

FONTE: Elaborado pelas autoras com base no CNPq | Plataforma Lattes (2016). 
CAPES. Também, houve a publicação de 288 livros e 785 capítulos de livros.

A quantidade de artigos indica uma quantidade média de 12 artigos, 2 livros e 6 capítulos de livro por doutor formado no PPGMADE no período analisado. Considerando uma margem de erro de $11 \%$, devido a curriculum Lattes não atualizado devidamente até o período da coleta de dados (meses de julho a setembro de 2016), pode-se concluir que a produção de alguns é bastante significativa - conforme apontam os dados da Tabela 1.

Para concluir esta parte deste texto, faz-se a verificação quanto ao tipo de produção bibliográfica, chegando à conclusão que o artigo científico é predominante em $61,79 \%$ dos casos, seguido da quantidade de capítulos de livros (27,96\%). Aqui, os dados mostram um resultado que não coincide muito com uma suposição anterior ao levantamento, de que haveria um número maior de livros publicados do que de capítulos de livros (Figura 6).

A distribuição da produção bibliográfica dos egressos do PPGMADE, no período em pauta, com predomínio do formato de artigo como produto mais frequente, indica um certo alinhamento ao que tem sido valorizado pelo sistema CAPES/CNPq - enfatizado pela pontuação conferida a cada produto - em comparação com outras formas de produção e de atuação científica ou atividades de extensão que um doutor pode realizar no âmbito da comunidade científica, ou da sociedade em geral. Portanto, neste quesito, verificou-se que o PPGMADE vem correspondendo ao que está sendo analisado como parte de uma atuação válida no âmbito dos programas de pós-graduação stricto sensu no país, dentre outros aspectos.

\section{Considerações finais}

Valorizando a perspectiva do efeito multiplicador, considera-se que um dos principais desafios para os programas de pós-graduação no Brasil será, cada vez mais, de elevar a qualidade do ensino superior por meio da capacitação dos docentes. Dessa forma, os cursos voltados à formação stricto sensu (mestrado e doutorado), devem valorizar tanto a atividade docente quanto a pesquisa, não se limitando ao encaminhamento único e exclusivo de pesquisadores para o mercado de trabalho. Ressalta-se, aqui, o papel do professor como multiplicador de oportunidades de abertura aos saberes em suas diferentes aplicações e contextos de prática, o que se vincula à essência do desenvolvimento e sua relação com o Meio Ambiente, em seu sentido amplo.

Ao desenvolver estudos a partir de uma problemática multidisciplinar e global, o PPGMADE aborda a relação entre Desenvolvimento e Meio Ambiente, abrangendo discussões entre vários contextos, global, nacional e local, que tanto se aprofundam no viés acadêmico de cunho fortemente teórico, quanto em relação às práticas cotidianas culturalmente produzidas ao longo de gerações e expostas às transformações do tempo e das sociedades. Essas discussões têm fortalecido novas abordagens, inclusive pela participação de alunos estrangeiros e das experiências como de convênio com instituição estrangeira. Este tipo de conexão internacional tem possibilitado a contribuição de professores em aulas, palestras, seminários e no trabalho de co-orientação em regime de cotutela, o que favorece o diálogo e troca de referências, de práticas e de ideias entre universidades localizadas em contextos diversos. 
É significativo que o tempo de elaboração das teses, em sua maioria, ocorra em até quatro anos, sendo este o prazo determinado como ideal pelas instâncias da administração federal. Este resultado, comparado com a qualidade das teses (algumas premiadas) pode, eventualmente, apontar para uma adequada condução dos estudos e atividades do programa.

Na elaboração das teses, percebe-se que os recortes espaciais de estudo têm se concentrado no Estado do Paraná e na Região Metropolitana de Curitiba, locais mais próximos da sede do PPGMADE em relação às opções nacionais ou internacionais, o que - eventualmente - pode ser entendido como fator facilitador do desenvolvimento do trabalho sob bases empíricas e mostrar o vínculo de dependência com fontes de financiamento e disponibilidade da relação tempo-custo-benefício.

Quanto ao número de formandos por turma, a seleção realizada em 2015 sinalizou uma ampliação significativa do número de vagas do programa, sendo a turma de doutorandos composta por 25 alunos, o que - provavelmente - irá resultar em aumento na produção bibliográfica, maior variedade das temáticas de estudo e ampliação do efeito multiplicador da formação madeana na sociedade.

Finalmente, verifica-se que a análise dos números obtidos demonstra a vitalidade do programa como um todo, com coerência entre a proposta didático-pedagógica lançada na criação do programa em 1993 e os resultados apresentados após duas décadas. A despeito das dificuldades da caminhada, tem havido uma produção concreta e efetiva, a qual favorece o fazer ciência com consciência, a aplicação da razão e pertinência para questionar o desenvolvimento e o meio ambiente, dialogando com os diferentes saberes na construção das sociedades - como destacam Gasque \& Tescarolo (2008).

Finalizando estas considerações, entende-se o seu caráter inicial no contexto de um processo que poderia ser continuado, com levantamentos, avaliações e atualizações sistemáticas e ajustadas às mudanças que se mostrem necessárias. Em pesquisas futuras, poderiam ser verificadas as razões para algumas situações - como a de baixo percentual de egressos que, até o momento, concluíram um pós-doutoramento, assim como a investigação dos motivos que levam à escolha do recorte espacial em relação a custos de deslocamento ou outras dificuldades, limitações ou possibilidades de ampliação dos recortes como suporte de análises mais integradoras.

Também, considera-se interessante a pesquisa que contribua no entendimento a respeito das condições para o egresso manter a produção bibliográfica, ou do que, e como o programa poderia apoiar para a continuidade dessa produção, além do questionamento quanto às dificuldades, condicionantes ou potencialidades a serem exploradas na prática profissional e, também, a não participação em funções e cargos de direção ou funções políticas.

Como explica Guareschi (1990), cabe considerar que a maior parte do que as pessoas assimilam e discutem nas ruas, e na vida do cotidiano, advém de conteúdos veiculados nas diversas formas de mídia. Isto nos leva a pensar a respeito das limitações impostas pelas condicionantes conjunturais, econômicas, políticas, culturais. Também, faz pensar no trabalho ainda a ser feito - a fim de ampliar o efeito multiplicador das atividades e conteúdos da produção científica oriunda de programas stricto sensu, junto ao cotidiano da maioria da população, incrementando oportunidades de aprendizado. 


\section{Referências}

Alves, J. E. D. Desafios da equidade de gênero no século XXI. Revista Estudos Feministas, 24(2), 629-638, 2016. doi: 10.1590/1805-9584-2016v24n2p629

CNPq - Conselho Nacional de Desenvolvimento Científico e Tecnológico. Censo Atual. Disponível em http://lattes. cnpq.br/web/dgp/censo-atual. Acesso: jul a set de 2016a.

$\mathrm{CNPq}$ - Conselho Nacional de Desenvolvimento Científico e Tecnológico. Lattes - Histórico. História do surgimento da plataforma Lattes. Disponível em: http://lattes.cnpq.br/web/ plataforma-lattes/historico. Acesso: jul de 2016b.

$\mathrm{CNPq}$ - Conselho Nacional de Desenvolvimento Científico e Tecnológico. Site oficial da Plataforma Lattes. Disponível em: http://lattes.cnpq.br. Acesso: jul a set de 2016c.

Floriani, D. Marcos Conceituais para o Desenvolvimento da Interdisciplinaridade. In: Philippi Jr., A.; Tucci, C. E. M.; Hogan, D. J.; Navegantes, R. Interdisciplinaridade em Ciências Ambientais. São Paulo: Signus Editora, p. 95-107, 2000.

Floriani, D. Ciências em transito, objetos complexos: práticas e discursos socioambientais. Ambiente \& Sociedade, IX(1), 65-80, 2006. Disponível em:

http:/www.scielo.br/pdf/asoc/v9n1/a04v9n1.pdf

Gasque, K. C. G. D.; Tescarolo, R. Por uma pedagogia do equilíbrio. Educação e Pesquisa, 34(1), 139-150, 2008.

Gatti, B. A. Reflexão sobre os desafios da pós-graduação: novas perspectivas sociais, conhecimento e poder. Revista Brasileira de Educação, 18, 108-154, 2001.

Gianneti, E. A civilização brasileira. Exame CEO. Ideias para quem decide, n. 7, p.16-33, 2010.

Guadilla, C. G. Universidade latino-americana: da casela vazia ao cenário socialmente sustentável. Cadernos de Pesquisa Fundação Carlos Chagas \& Cortez Editora, 101, 82-112, 1997.
Guareschi, P. A. Sociologia crítica: alternativas de mudança. Porto Alegre: Mundo Jovem, 1990.

Leff, E. Complexidade, interdisciplinaridade e saber ambiental. In: Philippi Jr., A.; Tucci, C. E. M.; Hogan, D. J.; Navegantes, R. Interdisciplinaridade em Ciências Ambientais. São Paulo: Signus Editora, p. 19-51, 2000.

Lima, C. de A.; Fortunato, R. A. Levantamento e organização de dados dos egressos do PPGMADE/UFPR entre 1993 a 2016. (Tabela Excel). Curitiba: PPGMADE, material inédito, 2016.

Lima, M. E. C. de C.; Geraldi, C. M. G.; Geraldi, J. W. $\mathrm{O}$ trabalho com narrativas na investigação em educação. Educação em Revista, 31(1), 17-44, 2015.

MCT - Ministério da Ciência e Tecnologia. Brasil está entre os 25 primeiros lugares no ranking de artigos cientificos. Disponível em <http://www.brasil.gov.br/ciencia-e-tecnologia. Acesso em 26 de setembro de 2016.

Moritz, G. de O.; Moritz, M. O.; Melo, P. A. A Pós-Graduação brasileira: evolução e principais desafios no ambiente de cenários prospectivos. In: Anais do XI Colóquio Internacional Sobre Gestão Universitária na América do Sul. Florianopolis, 2011. Disponível em: https://repositorio.ufsc. br/bitstream/handle/123456789/26136/5.30.pdf

Philippi Jr., A. Interdisciplinaridade como atributo da $C \& T$. In: Philippi Jr., A.; Tucci, C. E. M.; Hogan, D. J.; Navegantes, R. Interdisciplinaridade em Ciências Ambientais. São Paulo: Signus Editora, p. 3-14, 2000.

Raynaut, C.; Zanoni, M. (Eds.). Prefácio. Cadernos de Desenvolvimento e Meio Ambiente. Sociedade, Desenvolvimento, Meio Ambiente. Curitiba: UFPR, 1, 1994.

Rosa, M. I. de F. P. dos S.; Schnetzler, R. P. A investigação-ação na formação continuada de professores de ciências. Ciência \& Educação, 9(1), 27-39, 2003. 